\title{
Electron transfer Kinetics in a Deep Eutectic Solvent.
}

Fangchen Zhen, Lucie Percevault, Ludovic Paquin, Emmanuelle Limanton, Corinne Lagrost, Philippe Hapiot* Univ Rennes, CNRS, ISCR - UMR 6226, F-35000 Rennes, France

\section{1- Cyclic Voltammetry in Ethaline on Glassy Carbon Electrode.}

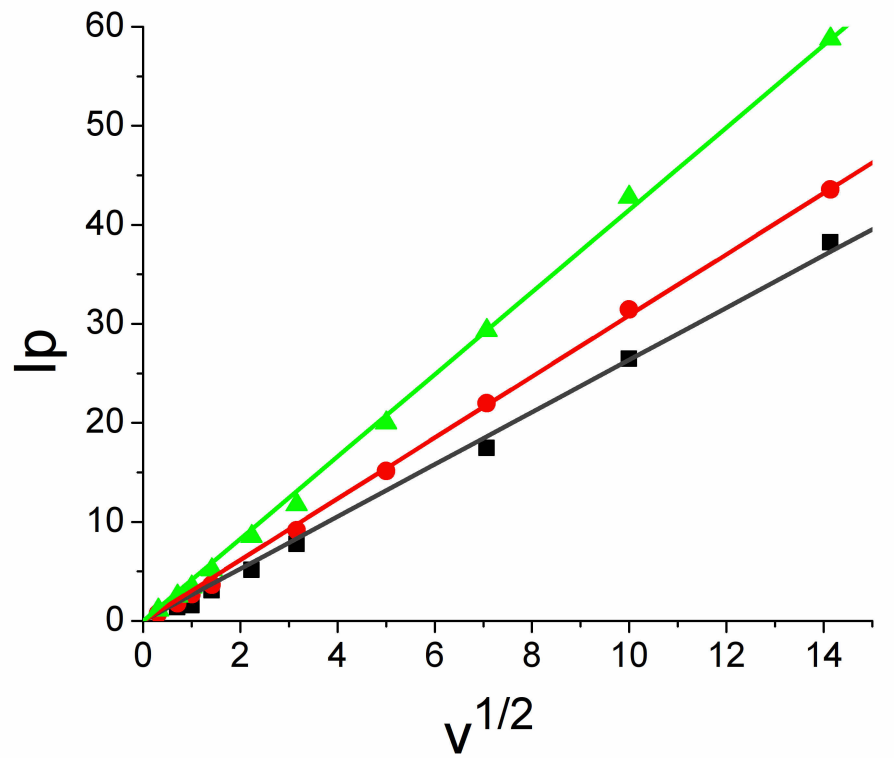

Figure S1. Cyclic voltammetry of the oxidation of ferrocene in Ethaline $\left(\mathrm{C}^{\circ}=210^{-3} \mathrm{~mol} \mathrm{~L}^{-1}\right)$. Variation of the peak current $I p(\mu \mathrm{A})$ with square root of scan rate $\mathrm{v}\left(\mathrm{v}\right.$ in $\left.\mathrm{V} \mathrm{s}^{-1}\right) . \mathrm{T}=298 \mathrm{~K}(\mathrm{Black})$, $313 \mathrm{~K}$ (red), $343 \mathrm{~K}$ (red).

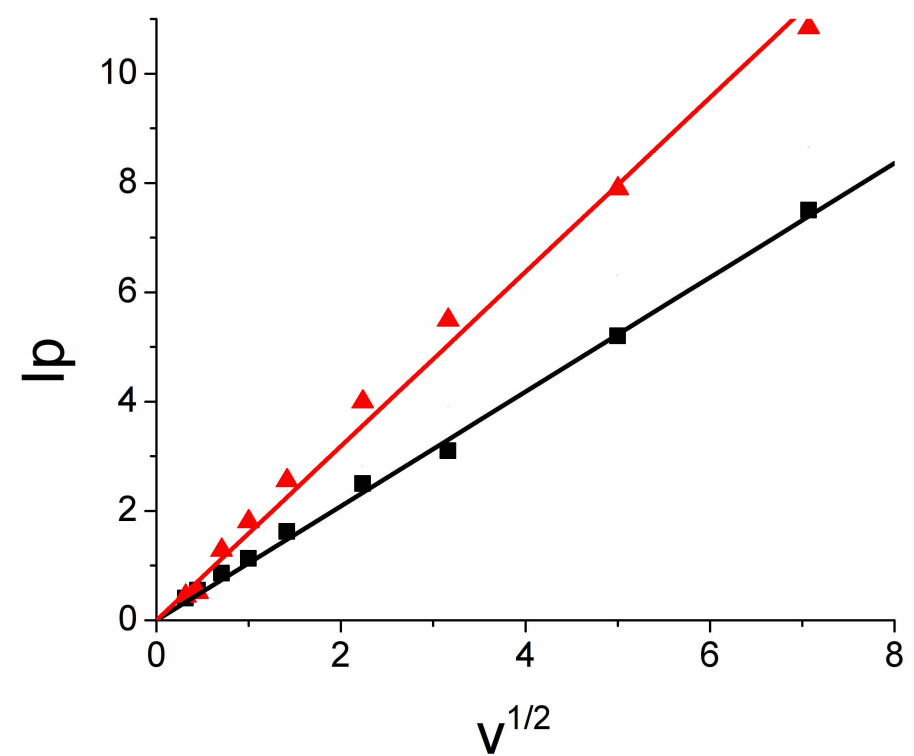

Figure S2. Cyclic voltammetry of Ferrocyanide in Ethaline $\left(\mathrm{C}^{\circ}=210^{-3} \mathrm{~mol} \mathrm{~L}^{-1}\right)$. Variation of the peak current $I p(\mu \mathrm{A})$ with square root of scan rate $v\left(v\right.$ in $\left.\mathrm{V} \mathrm{s}^{-1}\right) . \mathrm{T}=308 \mathrm{~K}$ (black), 333K (Red). 


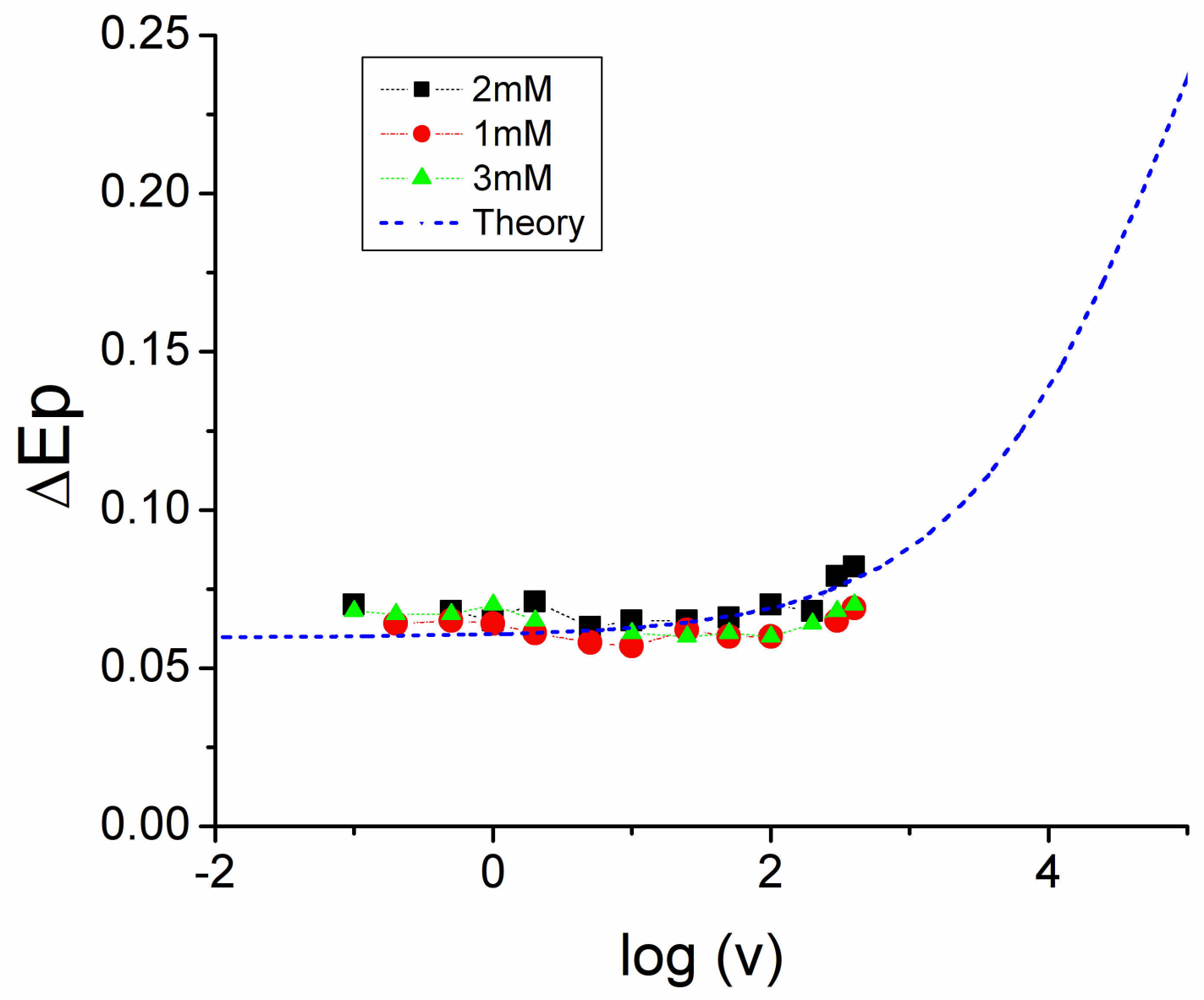

Figure S3. Variation of $\Delta \mathrm{Ep}$ in $\mathrm{mV}$ with the scan rates in $\mathrm{V}^{-1} \mathrm{~s}^{-1}$ for the oxidation of ferrocene in Ethaline at $313 \mathrm{~K}$ on a glassy carbon electrode.

Data were measured for different initial concentrations of ferrocene to test the efficiency of the ohmic drop compensation. 


\section{2- Cyclic Voltammetry in Ionic Liquids on Glassy Carbon Electrode.}
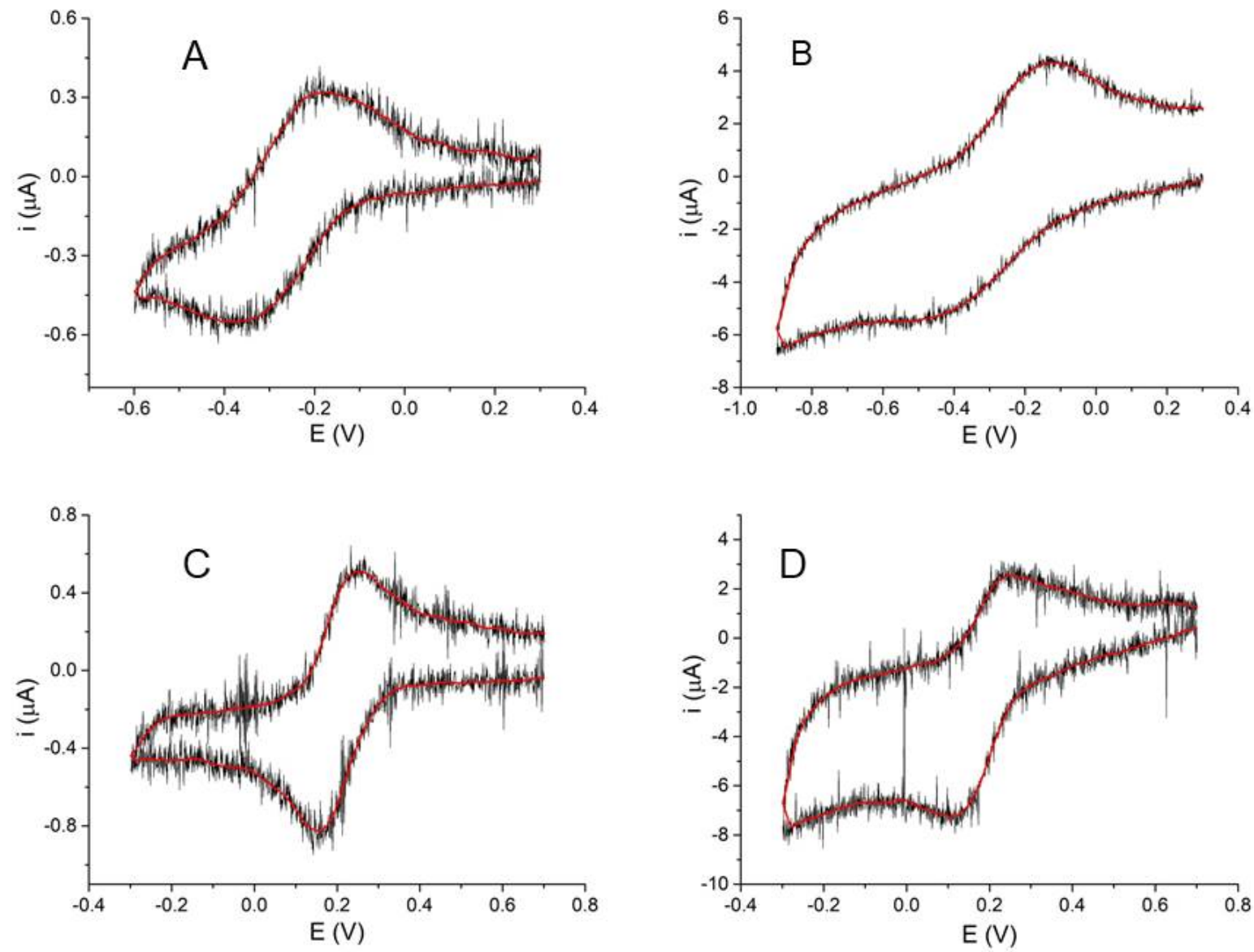

Figure S4. Cyclic voltammetry of $\mathrm{BMP}_{3}\left[\mathrm{Fe}(\mathrm{CN})_{6}\right]$ in 1-n-butyl-1-methylpyrrolidinium bis(trifluoromethylsulfonyl)imide (BMP-TFSI) (A,B) and in 1-ethyl-3-methylimidazolium tetrafluoroborate (EMMI-BF4). (C,D) Scan rate : $0.2 \mathrm{~V} \mathrm{~s}^{-1}(\mathrm{~A}, \mathrm{C}), 10 \mathrm{~V} \mathrm{~s}^{-1}$ (B,D). T= $303 \mathrm{~K}$. 


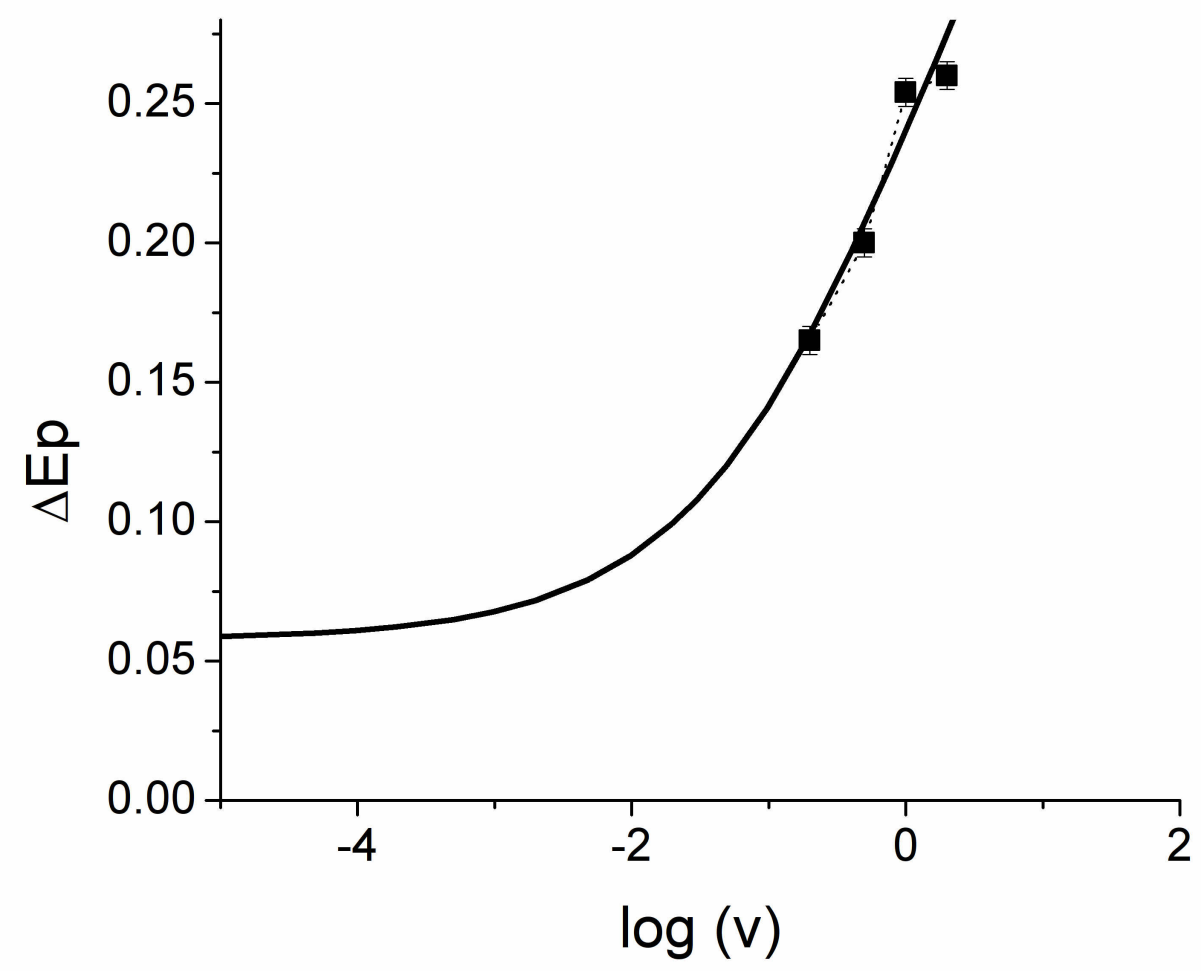

Figure S5. Variation of $\Delta \mathrm{Ep}$ for the reduction of ferricyanide in $\mathrm{BMP}-\mathrm{NTF}_{2} \mathrm{~T}=30^{\circ} \mathrm{C}$

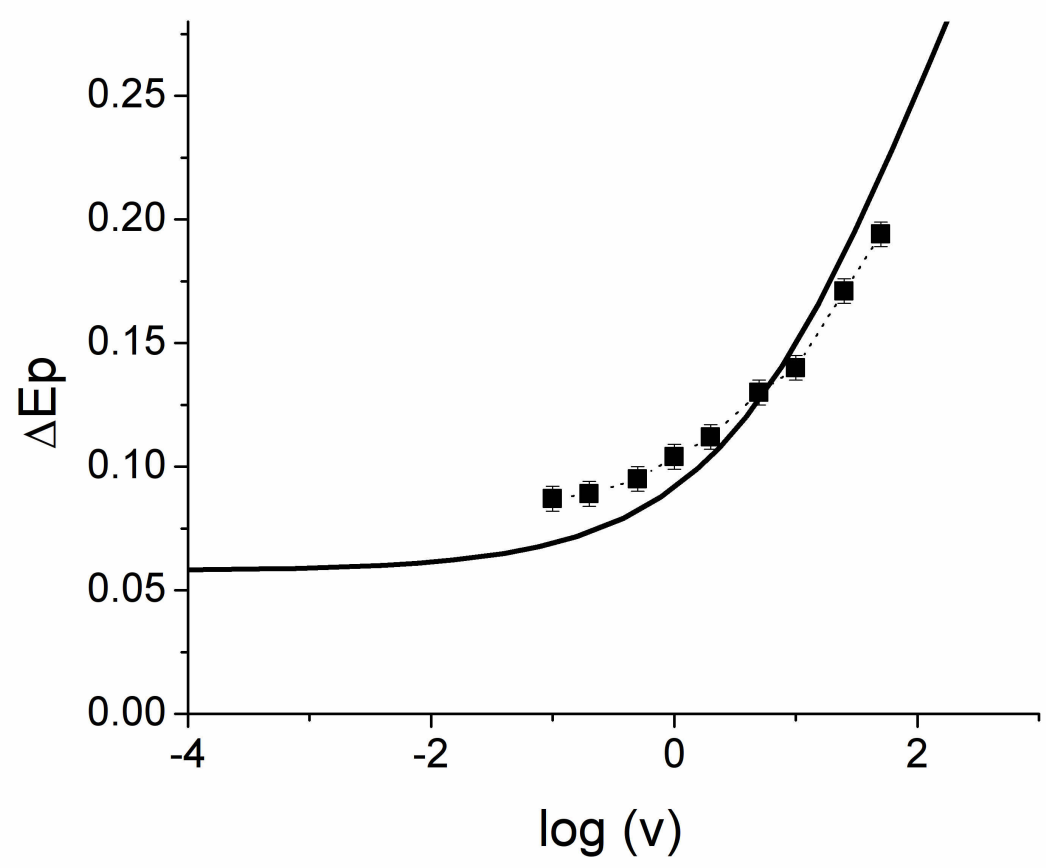

Figure S5. Variation of $\Delta \mathrm{Ep}$ for the reduction of ferricyanide in $\mathrm{EMMI}^{-B F_{4} .} \mathrm{T}=303 \mathrm{~K}$.. 
$\underline{3 \text { Measurement of rate constant } \mathbf{k}_{\underline{s}} .}$

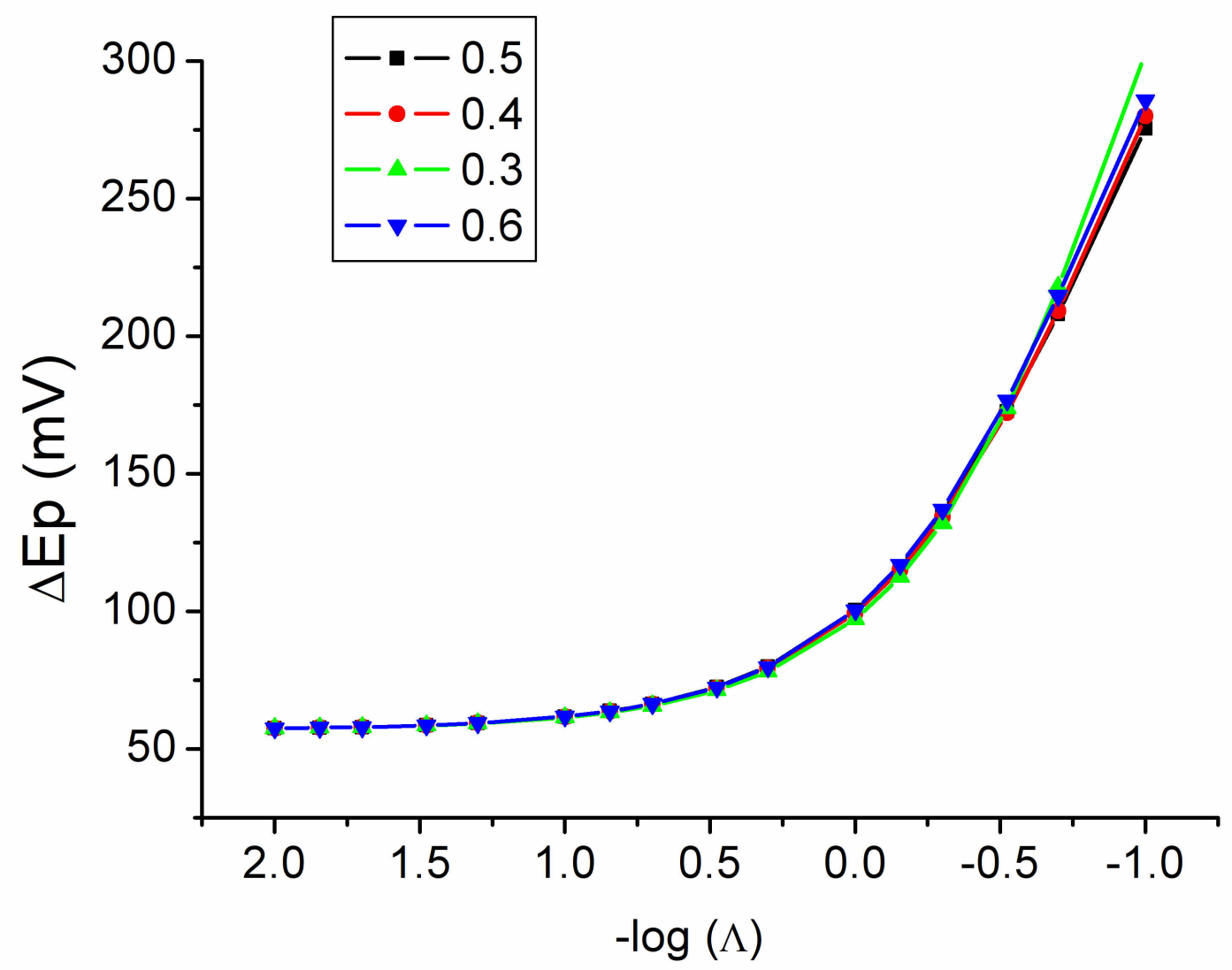

Figure S6. Theoretical variation of the peak to peak difference potentials as function of the dimentionless parameter $\Lambda=k_{s} / D^{1 / 2}(R T / \alpha F v)^{1 / 2}$ calculated for different values of the transfer coefficient $\alpha$ assuming a Buttler-Volmer law. Inversion potential is set as $500 \mathrm{mV}$ after the $\mathrm{E}^{\circ}$.

As seen on Figure S6, influence of the transfer coefficient $\alpha$ on $\Delta \mathrm{Ep}$ is negligible for $\Delta \mathrm{Ep}<300 \mathrm{mV}$ calculated for $0.3<\alpha<0.6$. 


\section{Characteristics of solvents dynamics}

Table S1.

\begin{tabular}{cccccc}
\hline Solvent & $\varepsilon_{S}$ & $\varepsilon_{\text {inf }}$ & $\varepsilon_{o p}{ }^{8}$ & $\tau_{\varepsilon \phi \phi}(p s)^{9}$ & $\tau_{L}(p s)$ \\
\hline Acetonitrile $^{1}$ & 37.5 & 2 & 1.8 & 3.3 & $\approx 0.2$ \\
Water $^{2}$ & 80 & & 1.78 & 9.3 & $\approx 0.2$ \\
BMPyr-TFSI $^{3}$ & 11.7 & 2.42 & 1.99 & 134 & $\approx 22$ \\
EMIM-BF $^{4,5}$ & 13.6 & 6.7 & 2 & 33.7 & 5.0 \\
EMIN-TFSI $^{5}$ & 12.3 & 4.7 & 2.02 & 41 & 6.7 \\
Ethaline $^{6}$ & 37 & 3 & $2.07^{10}$ & 71 & 4.0 \\
Ethylene Glycol $^{7}$ & 44 & 3 & 1.77 & 114 & 4.6 \\
\hline
\end{tabular}

1 - Role of Solvent Reorganization Dynamics in Electron-Transfer Processes. Anomalous Kinetics Behavior in Acohol Solvents. Mc Manis G.E ; Neal Golovin M.N. ; Weaver, M.J. J. Phys. Chem. 1986, 90, 6563.

2 - The mechanism of the dielectric relaxation in water. Ivan Popov, Paul Ben Ishai, Airat Khamzinb ,Yuri Feldman, Phys. Chem. Chem. Phys., 2016,18, 13941-13953

3 - The Dielectric Response of Room-Temperature Ionic Liquids: Effect of Cation Variation. Hermann Weingalrtner, Padmanabhan Sasisanker, Corinne Daguenet, Paul J. Dyson, Ingo Krossing,| John M. Slattery, and Thomas Schubert. J. Phys. Chem. B 2007, 111, 4775 - 4780.

4 - Estimation of the rate constant for electron transfer in room temperature ionic liquids. W. Ronald Fawcett, Attila Gaál, Daniel Misicak. J. Electroanal. Chemi. 660 (2011) 230-233.

5- Systematic Dielectric and NMR Study of the Ionic Liquid 1-Alkyl-3-Methyl Imidazolium. Kenji Nakamura and Toshiyuki Shikata. ChemPhysChem 2010, 11, 285 - 294

6 - Ionic conductivity of deep eutectic solvents: the role of orientational dynamics and glassy freezing. Daniel Reuter, Catharina Binder, Peter Lunkenheimer, Alois Loidl. Phys. Chem. Chem. Phys. 2019, 21, 6801- 6809. (Estimated from Figure 3 and Equation 2 in this reference).

7 - Dielectric Relaxation in Ethylene Glycol - Dimethyl Sulfoxide Mixtures as a Function of Composition and Temperature P. B. Undre, P. W. Khirade, V. S. Rajenimbalkar, S. N. Helambe and S. C. Mehrotra Journal of the Korean Chemical Society 2012, 56, 416-423.

8 - Calculated from their refractive indexes $n$ considering $\varepsilon_{o p}=n^{2}$.

9 - When several relaxation processes have reported, an effective harmonic relaxation time, $\tau_{\text {eff, }}$, is considered and calculated by averaging the frequencies of the relaxation mode weighted by its 
relative amplitude following Nakamura et al. approximation in reference 5 and discussed in reference 4.

10 - Densities and refractive indices of the deep eutectic solvents (choline chloride + ethylene glycol or glycerol) and their aqueous mixtures at the temperature ranging from 298.15 to $333.15 \mathrm{~K}$. Rhoda B. Leron, Allan N. Soriano, Meng-Hui Li. Journal of the Taiwan Institute of Chemical Engineers $2012,43,551-557$. 